\title{
A soberania popular revisitada: autogoverno como modo de vida*
}

\author{
Popular sovereignty revisited: self-government as way of life
}

\author{
Rúrion Melo \\ rurion@usp.br \\ (Universidade de São Paulo/CEBRAP, São Paulo, Brasil)
}

\begin{abstract}
Resumo: 0 conceito de soberania popular de Rousseau está vinculado a uma ideia radical de liberdade como autonomia: é livre aquele capaz de governar a si mesmo, não se submetendo à vontade de um outro. 0 presente artigo procura investigar o enraizamento social da autonomia não apenas como critério crítico de legitimidade política, mas tendo em vista compreender de que maneira ele se insere em contextos de ação da vida cotidiana da sociedade. Formas atuais de dominação social e novas gramáticas de lutas emancipatórias (em pautas ligadas ao feminismo radical ou às questões do antirracismo) mostram que a autonomia também precisa encontrar efetividade em dimensões sociais complementares à esfera pública política.
\end{abstract}

Palavras-chave: soberania popular; autonomia; esfera pública; reconhecimento; democracia radical; cultura política.

\begin{abstract}
Rousseau's concept of popular sovereignty is linked to a radical idea of freedom as autonomy: is free who can govern himself, not submitting to the will of another. This article investigates the social roots of autonomy not only as a critical criterion of political legitimacy, but in order to understand how it fits into action contexts of society's everyday life. Current forms of social domination and new grammars of emancipatory struggles (radical feminism or anti-racism) show that autonomy must also find effectivity in social dimensions that are complementary to the public political sphere.
\end{abstract}

Keywords: popular sovereignty; autonomy; public sphere; recognition; radical democracy; political culture.

Foram os teóricos realistas da política no século $X X$ que mais diretamente voltaram as costas para os ideais democráticos do autogoverno defendidos por Jean-Jaques Rousseau. Tanto Max Weber quanto Joseph Schumpeter analisaram as democracias contemporâneas de tal modo que a participação democrática e o ideal da soberania popular deram lugar a mecanismos institucionais formais e a processos de concorrência pelo poder (Weber, 2005; Schumpeter, 1975). Eles foram seguidos

\footnotetext{
* A primeira versão do presente texto foi apresentada no Colóquio Rousseau da UFSCar, em novembro de 2015. Agradeço a Marisa Lopes e Yara Frateschi pelo convite e pela organização do evento, em especial a Felipe Gonçalves Silva, Bruno Nadai e François Calori pelos comentários, críticas e sugestões.
} 
por muitos cientistas políticos, que indiretamente fundamentaram uma certa visão sobre as sociedades modernas e sobre a justificação racional da democracia com baixas pretensões normativas (Melo, 2011).

A perspectiva do realismo político está ancorada no diagnóstico mais amplo de uma modernidade política caracterizada pela existência de sociedades altamente complexas e pluralistas. Sociedades complexas (compostas por um Estado burocratizado, por uma economia de mercado desenvolvida e por uma sociedade civil fragmentada em grupos de interesse) possuem um alto grau de diferenciação funcional que acompanha a racionalização do direito, a concentração das empresas e a extensão da intervenção estatal sobre os mais diversos âmbitos da atividade humana. Sociedades plurais, que não contam com uma eticidade tradicional e comum, são regidas por uma multiplicidade de valores e interesses que na maior parte das vezes são irreconciliáveis entre si e ensejam uma individuação cada vez mais radical de formas de vida: cada indivíduo assume radicalmente a responsabilidade de avaliar os valores que orientarão suas decisões. Tal diagnóstico inviabilizaria a atualidade do conceito de soberania popular, sublinhando os muitos obstáculos da democracia como autogoverno (Przeworski, 2010).

De modo algum o argumento realista deixa de defender a democracia. Se sua concepção de democracia conta com um Estado racionalizado que pode impor limites aos riscos causados pelos ideais igualitários de liberdade política - ideais considerados vagos pelos realistas -, isso ocorre porque defendem, por outro lado, aspectos institucionais que apoiam a justificação de uma defesa do jogo democrático, mas isso sempre fundamentado em definições institucionais mínimas, tais como a manutenção de eleições periódicas, o princípio da maioria e procedimentos de tomadas de decisão. Para tais autores, o núcleo liberal instaurado nos mecanismos de funcionamento do sistema político é passível de justificação porque promove a organização democrática da concorrência entre grupos de interesse.

A perspectiva realista, altamente institucionalista, limitou o campo do político à figura privilegiada do Estado. O Estado, por definição como que antítese da soberania popular, reduz a sociedade política à centralidade da "burocracia". Burocracia é a dominação política que assume uma forma organizada, um poder administrativo altamente racionalizado. Por isso, a autoridade na condução da vida política passa para as mãos de "políticos profissionais", funcionários e especialistas que administram o aparato burocrático do Estado. Os interesses coletivos da sociedade política ficam subordinados às condições de competição política pelo poder administrativo, de sorte que o objetivo de assegurar o ideal da soberania popular é desmentido pelo modo como o poder administrativo se transforma em um fim em si mesmo. Neste quadro, a organização da vida política fica fadada a uma crescente burocratização e à centralização administrativa. 
A partir principalmente da década de 1970, a teoria política viu a entrada em cena de novos personagens (Arato e Cohen, 1991; Sader, 1991). Com a emergência de novos movimentos sociais e da sociedade civil organizada, a centralidade do Estado foi colocada em xeque, privilegiando-se o ponto de vista da "sociedade". De um lado, as teorias da representação política passaram a se abrir para dimensões institucionalizadas da participação e da deliberação dos cidadãos. De outro lado, as teorias dos movimentos sociais se ocuparam em medir os efeitos democratizantes das reivindicações políticas sobre as instituições formais do Estado de direito. Curiosamente, as ideias de Rousseau a respeito do autogoverno do povo, ainda que interessantes para o horizonte dos debates teóricos sobre novas demandas participativas, ficaram restritas a uma intuição normativa com fraca efetividade.

Não há dúvidas que Rousseau nos obriga a interpretar a democracia de uma maneira radicalmente diferente. Porém, não me parece que esta interpretação seja pouco plausível quando confrontada com diagnósticos de tempo. Ela implica, antes de tudo, pensar criticamente o princípio de legitimidade política sem que tenhamos de partir do Estado como centro de análise. Embora com nuances diferentes, os teóricos realistas da política e os defensores da participação institucionalizada precisaram vincular sua perspectiva ao papel do Estado. Pelo contrário, o conceito de soberania popular (e a categoria de autonomia que o sustenta) não está centrado no Estado enquanto tal. Minha hipótese é a de que justamente por esta razão tal conceito ainda poderia iluminar certos aspectos da discussão acerca da legitimidade política nas democracias atuais. Rousseau parece ter mais a nos dizer sobre a vida política das nossas democracias hoje do que os realistas e institucionalistas gostariam de reconhecer. A questão “o que é democracia hoje” pode obter uma resposta mais adequada se levar a sério novamente a perspectiva normativa de Rousseau sobre o autogoverno e a autonomia. Mas também aqui gostaria de avançar para além de uma concepção de autodeterminação política atrelada à emergência da sociedade civil e de movimentos sociais que assumem a expressão da liberdade política. Minha ideia consiste em compreender o enraizamento da autonomia - e a violação desta -em esferas sociais. Mas qual é exatamente o cerne normativo que Rousseau atribui à sua noção de liberdade?

Rousseau apresenta no Contrato social uma formulação radical de autonomia de acordo com a qual só é livre aquele que obedece a si mesmo. 0 paradoxo que o contrato social vem resolver permite que obediência e liberdade não se oponham conceitualmente no exercício soberano da vontade geral, de modo que o cidadão possa assumir os papéis de súdito e de soberano simultaneamente. ${ }^{1}$ Interessa a

1 “[A] essência do corpo político está no acordo entre a obediência e a liberdade, e as palavras súdito e soberano são correlações idênticas cuja ideia se reúne sob o termo único Cidadão" (Rousseau, 1964, p.249). 
Rousseau, antes de tudo, estabelecer um conceito de liberdade como autogoverno, de modo que só é "verdadeiramente senhor de si" aquele que obedece tão somente a lei que "se prescreveu a si mesmo" (Rousseau, 1964, p.187). Esta formulação exprime um princípio moral de legitimidade política com o qual podemos sopesar a validade do direito, a justiça e a injustiça das leis, e operar com uma espécie de "ideia reguladora" para avaliar criticamente as decisões e instituições do governo (cf. Fortes, 1976). Contudo, ela não compete tão somente à esfera jurídica ou à dimensão política, mas está mais profundamente inserida como critério crítico no interior das interações sociais cotidianas. ${ }^{2}$ Em outros termos, não avaliamos normativamente apenas o legislativo, o judiciário ou a administração do governo assumindo o ponto de vista da autonomia, isto é, colocando-nos no papel de cidadãos que se entendem tanto como destinatários das leis quanto na qualidade de seus próprios legisladores. Além disso, vivenciamos nas interações sociais a sujeição ao outro como falta de autonomia, como incapacidade de nos autogovernarmos cotidianamente. Mas podemos realmente sustentar que o autogoverno (com seus critérios de legitimidade e justiça) está ancorado em formas de autodeterminação e autorrealização socialmente constituídas?

Uma interpretação da autonomia com mais adensamento social vai nos exigir pensar a soberania popular de duas maneiras. E aqui eu sigo, ao menos inicialmente, a interpretação de Jürgen Habermas sobre a soberania popular e a autonomia com o intuito de vincular os traços normativos destes conceitos à dimensão social da “esfera pública” (Habermas, 1994, caps. 3 e 8). Em primeiro lugar, e este talvez seja o traço mais peculiar desta leitura de Habermas, a soberania popular não pode ser considerada de um ponto de vista substantivo, mas sim procedimental. Neste caso, há como que uma atitude performativa que faz com que os cidadãos, agindo de maneira autônoma, assumam simultaneamente o papel de destinatários e autores do direito. Esta seria uma reformulação do paradoxo de Rousseau que o contrato social viria solucionar (sermos, enquanto cidadãos, súditos e soberanos ao mesmo tempo, obediência e liberdade articuladas na concepção de soberania popular.) Com tal conceito de autonomia, Habermas frisou que os cidadãos não apenas reconhecem a validade do direito como simples ordens que lhes são impostas de maneira obrigatória, não exercem somente o papel de meros “destinatários” do Estado, mas também o de "autores" do direito.

Em segundo lugar, Habermas procura mostrar que em vez da concepção realista liberal tentar se imunizar contra toda e qualquer formação popular da opinião e da vontade, resguardando o núcleo institucional de uma política organizada, a justificação normativa da democracia decorre antes de tudo dos processos localizados

2 Em certa medida, sigo aqui a interpretação da autolegislação e do autogoverno no Contrato social apresentada por Neuhouser, 2008. 
no entorno do sistema político. A legitimidade do Estado de direito depende dos processos democráticos de formação política da vontade atrelados a uma formação porosa da opinião que, por princípio, é auto-organizada (Habermas, 1994, p.435 et. seq.). Habermas nos dá assim uma pista não apenas conceitual ao reelaborar a categoria de autonomia, mas também nos permite enriquecer o diagnóstico a respeito de processos políticos que são parte da vida democrática, os quais se deixam entender como expressão da soberania popular. Neste sentido, ele procura mostrar de que maneira o conceito de autonomia, rico em pretensões normativas, também encontraria adensamento em práticas sociais. Pois essa formulação de soberania popular como procedimento confluiria para seu conceito de esfera pública, permitindo assim articular a pretensão normativa da autonomia à dinâmica social em que percepções de problemas cotidianos, processos de influência, formas de autoorganização social e situações críticas são diagnosticadas. Esse conceito nos serve então para reinterpretar sociologicamente o núcleo normativo da autonomia e, junto com isso, entender as consequências normativas da atuação de movimentos sociais, associações livres e formas de auto-organização como partes mais marcantes dos fenômenos políticos atuais.

Juntando os dois conceitos, o de autonomia e o de esfera pública, poderíamos reatualizar o problema de Rousseau ligado ao autogoverno em dois aspectos. Em primeiro lugar, a atuação dos movimentos sociais e da sociedade civil pressionando o sistema político seria indício de que os cidadãos não desempenham somente o papel de destinatários, mas estão dispostos a se engajar em prol de sua autonomia. Pois eles não querem apenas se submeter às decisões impostas pelos governos, eles querem participar das contribuições e deliberações, querem protestar, reinterpretar valores (sobre temas diversos, sobre a família, a mulher, drogas, aborto, direitos), querem apresentar bons argumentos e desvalorizar outros, defendendo posições políticas divergentes (Habermas, 1994, cap.8). Além disso, a dimensão política de autodeterminação, de onde se produz o princípio normativo de legitimidade política, também está conectada estreitamente às condições sociais da liberdade como autonomia em esferas multidimensionais da vida. Interações sociais que reproduzem violência, discriminação e desrespeito entre as pessoas também são obstáculo para a realização de uma vida efetivamente democrática. Neste sentido, a legitimidade política está vinculada normativamente à experiência social e cotidiana da autonomia.

Evidentemente, reconhecer a atualidade de Rousseau neste sentido que estou sublinhando requer uma mudança de atitude por parte das teorias democráticas. Se quisermos dar conta dos problemas de legitimação do Estado de direito, algo com o qual a formulação de Rousseau nos ajudaria, a democracia não pode estar circunscrita a análises institucionais. Muito pelo contrário, ele ajudaria a trazer à tona aspectos de uma democracia radical, conceitualmente ligados à dimensão da autonomia e da 
soberania popular, que emergem junto a novas experiências políticas. Pois o ideal de autonomia estaria presente quando reconstruímos demandas atuais da sociedade pela democratização de instituições formais, novos modos de associação, mais qualidade de representação política. Sociologicamente, essas mudanças dependem do tipo de absorção e resposta institucional obtidas por pressão da sociedade. Em termos normativos, elas apontam para a gênese democrática das instituições, que pode ser reconstruída com as formas de expressão diversificadas que vêm da base da sociedade. E isso exige uma mudança de foco, uma sensibilidade da teoria da democracia para uma práxis política não limitada funcionalmente, que reconheça a riqueza da expressão da vida democrática da sociedade. Como dissemos, a teoria democrática bloqueou a possibilidade de incorporar a soberania popular porque permaneceu assumindo que entenderíamos melhor a democracia se mantivéssemos a análise política centrada no Estado. Segundo minha hipótese, que aponta em sentido contrário, tal reconstrução só será possível se a teoria democrática revalorizar práticas autônomas de auto-organização (Melo, 2016).

De modo algum isso requer simplificar a complexidade social. O próprio Habermas oferece um modelo teórico em que o conceito procedimental de soberania popular, que resguarda o cerne normativo da autonomia, pode ser conectado aos processos multidimensionais do espaço social da esfera pública. Como notou explicitamente, "é preciso desdobrar a substância normativa da autolegislação, que em Rousseau fora compactada em um único ato, em vários degraus de um processo de formação procedimental da opinião e da vontade" (Habermas, 1994, p.627). Isso significa levar em consideração deliberações em instâncias formais (parlamento, judiciário), mas também em diferentes dimensões associativas e de socialização cotidiana. A soberania popular começa, por exemplo, nas associações civis, nos bares, nas universidades e, por um longo caminho de circulação do poder em processos de interação social, poderia terminar exercendo pressão sobre o sistema político (idem, cap.8; Melo, 2015, 2016).

Ou seja, embora seja procedimental, a soberania popular não prescinde, diz Habermas, de um ancoramento na cultura política e na socialização (Habermas, 1994, pp.627-628). Deste modo, a democracia se constitui entre experiências e interações ordinárias (as quais entendo como dimensões de enraizamento social da autonomia) e as lutas e pressões sobre o sistema político propriamente dito. Mas a própria solução de Habermas, é preciso dizer, não avança nesta intuição. Não só porque, em certa medida, ainda parece se manter um bloqueio entre autonomia e os sistemas político e econômico. Mas principalmente sua teoria carece de mais aprofundamento para que possamos mergulhar na cultura política que forma a base da sociedade. É aí que uma noção ampliada de autonomia e soberania provavelmente precisaria ir. Pois o autogoverno, um traço normativo das sociedades políticas, também requer um modo 
cultural de vida, já que a cultura política pressuposta pelo conceito de autonomia também se efetiva em formas sociais de auto-organização. A soberania popular teria de ser estendida até tocar nos espaços coletivos de convivência e autorrealização, precisamente onde está fundada em termos substantivos. Claro que este passo requer uma compreensão extremamente ampliada do político. Neste caso, o político, o social e o cultural se reforçam, enriquecendo a referência tradicional de soberania popular.

Esta intenção teórica, a saber, a de radicalizar a tal ponto a autonomia até que a soberania popular seja incorporada nas formas de vida cotidianas da cultura política, retoma indiretamente algumas das análises de Jean Starobinski sobre Rousseau. Principalmente quando ele junta as preocupações do contrato social propriamente dito com as reflexões de Rousseau sobre associações civis, em especial as "festas" (Starobinski, 2011, pp.129-136). Tanto nas festas populares quanto no contrato, os homens se auto-organizam e se realizam de modo autônomo. "A exaltação da festa coletiva”, afirma Starobinski, "tem a mesma estrutura da vontade geral do Contrato social" (idem, p.134). Pois a "alegria pública" manifesta o momento de autoorganização por excelência, a imediata associação espontânea e livre, onde todos se encontram, ainda que temporariamente, em pé de igualdade (não importando os "uniformes" que vestem, se são ou não "senhores", ou se estão na presença do "pai”). ${ }^{3}$ Por esta razão, "a festa exprime no plano 'existencial' da afetividade tudo aquilo que o Contrato formula no plano da teoria do direito" (idem, p.135), replicando naqueles que festejam publicamente o papel de cidadão.

Refiro-me então à imagem da "festa" para sublinhar que a dimensão social da autonomia e da auto-organização da associação civil tem relação crucial com a qualidade da democracia. ${ }^{4} \mathrm{~A}$ vida democrática da sociedade apenas em parte se cristaliza nas instituições do sistema político. Porém, entendemos também o que é democracia se olhamos para as experiências dos sujeitos na base da sociedade e para as formas de "reconhecimento universal", segundo Starobinski, situadas socialmente. ${ }^{5}$ E atualmente estas experiências encontram sua expressão nas linguagens ordinárias da religião, da arte, da literatura, da música, da internet e das redes sociais, entre outras linguagens comuns, vinculando na esfera pública gramáticas existenciais que

\footnotetext{
3 Para uma investigação da relação entre a experiência da festa e sua consequência também em modos de associação política, cf. Magnani, 1984.

4 Pois na festa e no contrato Rousseau manteria a forma da autoassociação, isto é, as "condições da associação civil". Pois "o povo submetido às leis deve ser o autor delas; somente aos que se associam compete regulamentar as condições da sociedade" (Rousseau, 1964, p.202). Assim, mantem-se a analogia com a soberania popular segundo o princípio da autonomia, pensado aqui a partir das condições auto-organizativas da associação civil.

5 "O que o Contrato estipula no plano da vontade e do ter, a festa realiza no plano do olhar e do ser: cada um é 'alienado' no olhar dos outros, e cada um é restituído a si mesmo por um 'reconhecimento' universal” (Starobinski, 2011, p.135).
} 
se entrelaçam com a política. Elas constituem a base dos processos de formação da opinião e da vontade, o que significa que não podem ser desprezadas a título de experiências dessa soberania popular revisitada. Assim como a gênese da autonomia privada remete a expectativas de autorrealização individual, a autonomia política está apoiada na experiência prática da vida cotidiana, nos espaços sociais e intermediários de socialização e convivência em que os sujeitos se "autogovernam" socialmente, por assim dizer. ${ }^{6}$

O enraizamento social da autonomia depende certamente de algum tipo de ethos democrático, disputado em diferentes dimensões da vida social. Tal ethos é configurado junto com experiências sociais e culturais que de algum modo se mostram favoráveis à autonomia. Podemos falar de uma "cultura da autonomia", para usar a expressão de Manuel Castells, quando os atores sociais se tornam sujeitos nos processos sociais com liberdade, ou seja, sem se submeterem a dinâmicas unilaterais de controle e dominação. Trata-se de uma cultura que tem se constituído tendencialmente em "todos os domínios da vida social” (no trabalho, na mídia, na internet, no mercado, na educação, na saúde, no governo, na política etc.). Mas o exemplo da internet é central na leitura de Castells porque ressalta de que maneira são criadas cotidianamente condições para uma forma prática de auto-organização. "A autonomia", afirma Castells, "refere-se à capacidade de um ator social tornarse sujeito ao definir sua ação em torno de projetos elaborados independentemente das instituições da sociedade, segundo seus próprios valores e interesses" (Castells, 2013, p.172). A internet forneceria a plataforma de comunicação auto-organizada capaz de criar uma cultura formada em práticas autônomas e em grande medida descentralizadas (configurando-se na construção autônoma de redes sociais controladas e guiadas por seus usuários). ${ }^{7}$

A soberania popular, portanto, não se caracteriza apenas do ponto de vista da práxis autônoma, isto é, de uma visão procedimental, para seguir a interpretação de Habermas, em que a formação da opinião e da vontade, porosa e descentrada, assume o contorno de associações capazes de se cristalizar em esferas públicas autônomas. Mesmo uma soberania popular reconstruída de acordo com seus elementos

6 Apoio-me aqui na interpretação que Felipe Gonçalves Silva faz do conceito de "autonomia privada" em Habermas, procurando, na medida do possível, aproximar o quadro jurídico-político do conceito à dimensão social da democracia. Cf. Silva, 2016.

7 A relação da cultura de fundo com a política é um dos pontos centrais: "Há uma conexão fundamental, mais profunda, entre a internet e os movimentos sociais em rede: eles comungam de uma cultura específica, a cultura da autonomia, a matriz básica das sociedades contemporâneas. Os movimentos sociais, embora surjam do sofrimento das pessoas, são distintos dos movimentos de protesto. Eles são essencialmente movimentos culturais (...). Os movimentos que observamos encarnam o projeto fundamental de transformar pessoas em sujeitos de suas próprias vidas, ao afirmar sua autonomia em relação às instituições da sociedade" (Castells, 2013, p.171). Cf. também a introdução de 2013, sobre redes digitais e a cultura da autonomia, para a nova edição de 0 poder da comunicação em Castells, 2015. 
procedimentais também deve ser compreendida como um espaço social entrelaçado de experiências práticas difusas, de conflitos e aspirações, os quais compõem uma cultura política determinada. A esfera pública (sempre plural) está configurada com base no cruzamento de histórias de vida, narrativas, informações, ou seja, de experiências de interação em que se formam os diversos "públicos". 0 cruzamento dessas experiências, que do ponto de vista da teoria crítica são acentuadas segundo a vivência negativa desses espaços e dimensões de interação, constitui assim a gênese social da própria autonomia.

Portanto, o conceito revisitado de soberania popular, tal como estou sugerindo, não limita o princípio do autogoverno a critérios normativos erguidos diante de decisões de governantes. Não se limita a um ideal com o qual poderíamos avaliar criticamente a justiça ou injustiça de uma sociedade estritamente política. Pelo contrário, o autogoverno deve poder ser interpretado como um modo de vida. Autogoverno também serve de crítica para experiências e sujeição da dominação presente no "social". Como lembra Habermas, a soberania popular pressupõe uma cultura política composta de cidadãos acostumados com a liberdade. Mas isso precisa de fato ser teoricamente compreendido e assimilado pelas teorias da democracia. Mesmo se contássemos com instituições legalmente estáveis e bem avaliadas do ponto de vista da democracia política, não seria possível afirmar que vivemos de fato em uma sociedade democrática se continuamos convivendo com experiências sociais de racismo, sexismo, ou outros tipos de violação social da autonomia. Ter autonomia significa não se submeter à dominação e à violência nos diversos contextos sociais da vida (na família, na escola, no trabalho, na universidade etc.). Implica, portanto, poder se autogovernar (ou seja, a capacidade de se autorrealizar e se autodeterminar) no cotidiano de suas interações sociais.

Axel Honneth toca no mesmo tipo de problema de maneira frutífera. A expectativa de Rousseau (embora seu modelo se baseie antes de tudo em Hegel) de pensar o autogoverno como autorrealização e autodeterminação precisa estar atrelada a um diagnóstico sobre as condições sociais da liberdade. Com o conceito de "liberdade social", Honneth mergulha a autonomia na "eticidade democrática", isto é, a sedimenta nas diferentes esferas de ação e nas práticas e costumes cotidianos (Honneth, 2011). Sua exposição nos ajuda a ver que a dimensão política da formação da vontade também é dependente do modo de efetivação da liberdade em outros contextos de vida. Nossa "cultura política democrática" conta, portanto, com uma "complementação recíproca" de ações e práticas que formam a teia de experiências e pretensões normativas de fundo. ${ }^{8}$

8 "O Sistema social da eticidade democrática constitui uma complexa rede de dependências recíprocas, na qual a realização da liberdade em uma esfera de ação depende de que nas outras esferas também sejam realizados os princípios de liberdade fundamentais em cada caso; o participante livre no mercado, o participante de uma cidadania autoconscientemente democrática e o membro da família 
É preciso destacar na formulação honnethiana da liberdade social que a questão da legitimidade deixa de estar atrelada à dimensão jurídico-política por excelência: tanto na esfera pública quanto nas dimensões "privadas", a medida do autogoverno se enraizou como critério socialmente produzido. As violações sistemáticas contra a autonomia das pessoas revelam assim, junto à percepção negativa que trazem para os próprios concernidos, que a liberdade é uma medida socialmente vigente, ainda que não plenamente realizada em todas as dimensões da vida. Tais violações, vividas nas mais diversas dimensões da sociedade, lançam luz às pretensões normativas imanentes às práticas sociais enquanto tais, levando a consequências importantes para a qualidade de nossa vida democrática. Já que o processo democrático, cuja pretensão normativa de legitimidade pode mais facilmente ser compreendido segundo o princípio de autonomia, sobrepõe-se às aspirações à liberdade em outras esferas de ação. Podemos ver então que há um entrelaçamento entre tais âmbitos na medida em que a própria disputa na esfera pública (por direitos, por participação política etc.) avançaria em termos emancipatórios junto à efetivação cada vez maior da liberdade em outros domínios das interações sociais.

É preciso sublinhar que o enraizamento social da autonomia só é capaz de trazer à tona seu núcleo normativo à luz de experiências de heteronomia. Ou seja, tais experiências negativas ${ }^{9}$ revelam que modos de vida autônomos estão em risco. Por esta razão, as indignações e tematizações públicas de movimentos sociais lançam luz ao desrespeito sistemático da autonomia. Foram as teóricas feministas que, no campo das teorias democráticas, mais avançaram nesta direção (Biroli e Miguel, 2014). Elas mostraram que apenas com o enraizamento de uma cultura política que valoriza formas autônomas de vida é possível reconhecer experiências de opressão, exclusão e dominação socialmente produzidas. A libertação das mulheres está ligada a comportamentos e atitudes cotidianas, nos espaços e interações em que as experiências negativas de desrespeito são vivenciadas e também onde acontecem as lutas em prol do reconhecimento e da autonomia (como em casa, no trabalho, clubes, igrejas ou outras associações). As mulheres procuram se auto-organizar de maneira crítica e conduzir autonomamente a própria vida, lutando cotidianamente para superar estereótipos e atitudes sexistas vigentes (Fraser, 1989).

Os exemplos poderiam variar bastante, e seriam muitos exemplos. Minha conclusão é apenas teórica, e é bem modesta. O paradoxo de Rousseau não está ausente das democracias, mas mais presente do que nunca. Para reconhecer isso, nossa perspectiva teórica tem de mudar radicalmente. Ela precisa olhar a política e o direito de uma perspectiva mais "societária", permitindo-nos compreender de

emancipado são figuras que representam, para a esfera correspondente, ideais institucionalizados em nossa sociedade a se condicionar reciprocamente, uma vez que as propriedades de um, em última instância, já não podem ser realizadas sem as dos outros dois" (Honneth, 2011, p.616).

9 Em analogia com o estatuto das experiências de desrespeito na abordagem de Honneth, 2003. 
maneira crítica a vontade livre de dentro das esferas sociais. Afinal, a vida democrática e a própria soberania popular permanecem em risco se as experiências nas relações íntimas, no mercado de trabalho em geral e na própria esfera pública política são constituídas pelo desrespeito, dominação e violência constantes. Para saber o que é democracia temos de colocar novamente em cena a soberania popular e a autonomia que ela pressupõe, mas só permaneceremos “tão livre quanto antes”, como já disse Rousseau, se o critério de autogoverno que rege ficticiamente o contrato social estiver efetivamente enraizado nas experiências que se encontram na base da sociedade e que sustentam toda e qualquer legitimidade de uma vida democrática.

\section{Referências}

Arato, A. e Cohen, J. (1991). Civil Society and Political Theory. Cambridge, MA: MIT Press.

Birolli, F. e Miguel, L. F. (2014). Feminismo e política: Uma introdução. São Paulo: Boitempo.

Castells, M. (2013). Redes de indignação e esperança: Movimentos sociais na era da internet. Rio de Janeiro: Zahar.

Terra.

Fortes, L. R. S. (1976). Rousseau: Da teoria à prática. São Paulo: Ática.

Fraser, N. (1989). “Struggle over needs”. In: Unruly Practices. Oxford.

Habermas, J. (1994). Faktizität und Geltung. Frankfurt am Main: Suhrkamp.

Honneth, A. (2003). Luta por reconhecimento: A gramática moral dos conflitos sociais. Tradução de Luiz Repa. São Paulo: Editora 34. - (2011) Das Recht der Freiheit. Berlin: Suhrkamp.

Magnani, J. G. (1984). Festa no pedaço. Rio de Janeiro: Brasiliense.

Melo, R. (2011). "Teorias contemporâneas da democracia: Entre realismo político e conepções normativas”. In: Y. Frateschi; R. Melo; F. C. Ramos (org.). Manual de filosofia política. São Paulo: Saraiva.

- (2015). Repensando a esfera pública: Esboço de uma teoria crítica da democracia. Lua Nova, 94, pp.1-39.

. (2016). O 'Paradoxo’ da democracia radical. Doispontos, 13, pp.71-82.

Neuhouser, F. (2008). Rousseau's Theodicy of Self-Love: Evil, Rationality, and the Drive for Recognition. Oxford: Oxford University Press.

Przeworski, A. (2010). Democracy and the Limits of Self-Government. Cambridge: Cambridge University Press.

Rousseau, J- J. (1964). Du Contrat social. Paris: Gallimard.

Sader, E. (1988). Quando novos personagens entraram em cena. Rio de Janeiro: Paz e Terra. 
Schumpeter, J. (1975). Capitalism, socialism and democracy. New York: Harper.

Starobinski, J. (2011). Jean-Jaques Rousseau: A transparência e o obstáculo. São Paulo: Companhia das Letras.

Silva, F. G. (2016). Liberdades em disputa: A reconstrução da autonomia privada na teoria crítica de Jürgen Habermas. São Paulo: Saraiva.

Weber, M. (2005). Ciência e política: Duas vocações. São Paulo: Cultrix.

Recebido em: 19.10.2016

Aceito em: 20.11.2016 